\title{
Birth Order, Traits and Emotions in the Sibling System as Predictive Factors of Couple Relationships
}

\author{
Hadas Doron
}

Tel Hai Academic College, Israel

\begin{abstract}
The objective of this study is to examine the connection between an individual's traits, emotional functioning and role division - which are influenced by birth order in the family of origin - and traits, emotional functioning and role division in the later spousal-couple context. 69 subjects which are either first-borns, middle or youngest children in their family of origin, were administered questionnaires measuring traits and emotions in both their past sibling and present couple system. Additionally, a role division questionnaire measured role division in their couple system. According to study's hypothesis, a correlation was found between the emotions expressed in the sibling system and in the couple system; traits were found to be correlated between the sibling and the couple systems only for first-borns and middle children. Contrary to research's hypothesis, no effect was found of birth order, on role division in the couple system. The findings' practical and methodological implications are discussed.
\end{abstract}

Keywords: Birth order, sibling relations, couple relationship, sibling role division.

\section{INTRODUCTION}

Our first partners in our childhood are our siblings. Our relations with them even in childhood includes components which will later become significant in our couple relationships as adults. Some of these components include: mutual dependence and autonomy, role division, emotional communication and problem solving, agreement and conflict, loyalty and envy, cooperation and competition/rivalry [1].

There are numerous theories that address the couple relationship. Some theories focus on the family of origin in general, and the relationship of the spouses with their parents, in specific, as affecting later spousal relationship. For example, Amato [2] studied the long term influences of parental and familial instability, on offspring's later spousal satisfaction and stability. Other theories deal with the formation of the couple relationship and its realm: attachment style, conflict resolution, mutual expectations and more. However, among the theories focusing on the family of origin, little has been written on the sibling connection.

The sibling relationship is the longest relationship in the human life: it begins in childhood, continues throughout life and only ends with the death of one of the siblings. Siblings treat each other in a variety of ways; the relationship can include love and hatred, concern and abuse, loyalty and betrayal. There may be power struggles, dependency, support, affection, experimental roles and more. Some or all of these components are likely to play a part in shaping the individual's relationship with a partner in his/her adulthood, including the following aspects: expectations of the couple relationship, self- perception in the relationship and intimate relations with others. In short, the couple relationship in

*Address correspondence to this author at the Tel Hai Academic College, Israel; Tel: 9724 9890404; Fax: 9724 9894261;

E-mail: hadasdoron@012.net.il adulthood contains components similar to those that typify the sibling relationship that begins in childhood [3]

Theories dealing with personal development tend to focus mainly on the parent-child relationship and less on sibling relationships. Despite support in the theoretical, clinical and research literature regarding the importance of sibling relations and its effect on building intimate relationships in adulthood, little research has addressed this subject though there is no doubt that siblings represent significant attachment figures who influence developmental processes. Siblings who grow up together are easily available objects for comparison and conflict. Siblings acquire behavioral patterns in close interpersonal relationships via joint sibling activities, role-playing and sibling responses to one another.

\section{LITERARY OVERVIEW}

\section{The Sibling System}

The sibling unit is a subsystem within the family which includes components that exist between people who are related. In the last two decades, much clinical and research attention has been focused on the sibling relationship as having great effect on the individual's identity formation and future relationships. These sibling relations encompass a wide variety of emotional experiences as well as coping experiences that influence the individual's self-perception and creation of future relationships [4]. Bank and Kahn [5] depict the sibling relationship as encompassing two critical, significant coping styles of intimate relations between people: the individual's ability to live separately and independently from another yet at the same time to experience closeness, intimacy and dependence. Bank and Kahn [5] claim that sibling relations affect these abilities through coping with issues of individuation and integration as they occur in childhood and continue to make their appearance throughout puberty and adulthood.

From the moment of birth, the infant is hungry for affection, connection and attention. Siblings who are available 
and close in age can be an important source for satisfying these needs and constituting attachment figures. The sibling relation can also constitute a secure source of support, trust and security--as well as a source of abuse and extreme mistrust [4]. Bozard and Boll [6] following their study of large families (with numerous children), claim that when parents are tired and overwhelmed, the children turn to their older siblings for help. Minuchin [7], in his work with families in distress, found that the lack of functioning parental figures is a factor in strengthening the significance of the sibling relation. They claim that: 1) Siblings are figures who compare and reflect each other's traits, which are essential steps for formation of identity. 2) Siblings turned to one another for protection when the parents were absent. 3) Siblings united together in a group when an outside threat appeared.

Bank and Kahn [5] emphasize the importance of the individuation-integration process taking place in the sibling dynamics, citing three styles of sibling identity: "great identification"--which emphasizes the similarities between siblings and denies variations; "partial identification"--which emphasizes both similarities as well as differences between sibs; and "distant identification" which emphasizes the differences. It seems that many children derive directly from the sibling experience the basis for what they want (or don't want) to be as individuals, as partners and as a friends in a peer group.

The sibling subsystem, like any system, has specific rules and members learn to obey these acquired conventions. Siblings act as socializing agents, social teachers and models for social behavior. They erect and strengthen standards, serve as models for emulation and advice-giving and are careful to create clear roles for each member--a process that usually transpires in relationships of friends or marital partners [5].

\section{Birth Order and Sibling Relations}

One of the approaches that developed out of the psychoanalytic theory is Alfred Adler's approach (1870-1937). Adler [8], the father of individualistic psychology felt that all human beings have aspirations for maximal selfimprovement. Adler claimed that human beings are driven to aspire to perfection, and this drive is based on feelings of inferiority rooted in childhood. Adler's concept of "lifestyle" includes biological data, conscious and unconscious drives, a history of experimentation and life objectives [9], birth order and the position of the child in the initial family - all these influence and mold the character and personality of the child and constitute a significant part of the formation of a "lifestyle" $[10,11]$.

Adler characterizes four positions in the birth order of a family: the firstborn--spends some time as the only child in the family, during which he/she receives maximal attention and love from parents without a competitor. When the next child is born, there is competition and the firstborn feels envious and comes face to face with powerful emotions of deprivation. The firstborn is liable to use all possible means at his disposal to achieve his parent's love, because he may feel rejected by the parents. Another claim is that the firstborn often develops a conservative approach in life and grows up to oppose all changes or innovations, since the first change in his life caused him much discomfort. Adler claims that when firstborns reach adulthood they yield to those in charge of them, but strictly control those under them. He says that many firstborns learn to imitate their parents and play the role of the parent, thus developing responsibility and the desire to protect and help others. Firstborns also develop great skill in management and organization [8]. The middle child--described by Adler as the one who races against the older sib, without any chance of catching up, but simultaneously faces the younger sib who is trying to catch up to him. The middle child has great ambition and is full of competitive spirit as he/she must compete over and over for attention and prove himself. The middle one tends to set unrealistic objectives for himself that will later lead him to certain failure [12]. Youngest--Adler holds that the youngest is in the optimum position. True, other children have preceded $\mathrm{him} / \mathrm{her}$, but no one is running after him and those who preceded him already paved the way; the parents acquired parental skills at the expense of the older siblings. Adler claims that the youngest is usually pampered but simultaneously full of great initiative and independence, sometimes even developing tendencies that are not accepted by the other family members. The youngest is very ambitious. Only child--Adler believes that this child is in the worst position as he/she is pampered, used to receiving attention and having parents fulfill his demands. He is not independent and has difficulty in delaying gratification. As adults, only children demand much love from their partners without being willing to give love in return [8].

There are some hypotheses originating in Adler's theory that are worthy of being tested. Adler's biggest contribution to the birth-order field lies in his conceptual notion that the oldest, middle and youngest children in a family have different personalities and the differences between them are related to the different and unique experiences of each child as a member of a social group. In other words: children of different birth order tend towards different interaction patterns in the family and as a result, undergo different social learning experiences outside it [13].

Theories regarding birth order and especially Adler's theory provided the basis for many of the studies in this domain. Joint personality traits were found for firstborn children, traits that appeared with great frequency in the studies, such as: high achievement [14]; high intelligence quota (IQ) [15]; higher need and motivation to succeed [16]. The middle child is considered the most sociable and with the greatest feeling of belonging or kinship. The youngest is the one possessing the most empathy [17].

Other variables connected to human development which were studied in relation to birth order, include: the intellectual level of the child [18], development of the self in early childhood [19], intellectual achievements in late childhood [3], and mother-child relationship [13].

\section{Power Relations Between Siblings}

Birth order in a family is an important variable in understanding power relations between siblings. For example, the attitude towards discipline is different for each child within the family. The firstborn generally has a position of authority and responsibility. Then, when the younger child demands equal treatment, the firstborn sibling grapples with the inevitable change in status and power [5]. Parents often expect the eldest child to have a higher level of discipline than the others; as a 
result, he or she often receives the most reprimands and punishments. That is the reason that firstborns generally become serious adults with greater self-discipline. Firstborns tend to be peacemakers yet also hostile towards their siblings [5].

Dunn [20] strengthens this claim and adds that firstborn sibs feel more hostility towards their siblings because they themselves experienced strict discipline from the parents. As adults, firstborns tend to express more ambivalence and hostility towards their sibs than the younger sibs show towards them. According to Sutton Smith's study (in Dunn, [20]), when there is conflict between siblings, the older sibs tend to use techniques of status and bribery while the younger ones react with angry faces, self-justification and tears.

Power relations transpire when the firstborn points an incriminating finger at the younger sib who took his place. The main objective of power struggles is to be rewarded with parental attention, a need arising mainly from the appearance of the second child [20].

Although Patterson and Zigler [21] argue that the firstborn experiences more stress and anxiety due to the threat of being usurped by the younger siblings, Brody [22] holds that the firstborn is precisely the one to arouse anxiety and fear in the younger children, through punishing the them for their very existence; therefore, one can claim that jealousy, rivalry and competitiveness between siblings is reciprocal and that different researchers simply emphasize different aspects of the rivalry as being more dominant among the firstborn or later child [13].

\section{Role Division}

Various variables affect the sibling position and relationship. Structural variables include birth order, age differences and gender of the sibs. Social variables that influence the roles assumed by the sibs include caregiver-care receiver, teacherstudent etc as well as social elements of competition and friendship [23]. Fishler [13] claims that firstborns need more social validation because they are used to receive social reinforcement in greater doses than other children, which in turn interfere in preparing them towards independence. On the other hand, some studies claim that since firstborns assume a dominant role in family interactions they become mature and responsible earlier than the others. Newman [24] explains that people's dependence on others as sources of approval, assistance and attention does not necessarily contradict independence in daily functioning. Hilton argues for a distinction between psychological independence and the physical expression of independence, that is, the assumption of responsible roles [24].

\section{The Couple and Sibling Relationships}

The connection between sibling and couple relationships may be viewed through two theoretical viewpoints: attachment theory and social learning theory. According to Bowlby's attachment theory [25], internalized models of early relations in the family influence relationships later on in life and beyond the parameters of the original family unit. This theory emphasizes the importance of early relationships with the caregiver as a basis for the model of the person's relationships in the future. Many of the studies dealing with the attachment theory focus on the influence of the mother-child relation upon sibling relationship [26].
According to Bandura's social learning theory [27], the acquiring of interpersonal behaviors within the family, influences relationships with others outside the family.

Despite the fact that each of the theories above has a different starting point, each of them asserts that an individual's past experiences affect his or her relationships both in the present and in the future. The professional literature does not boast a large number of studies dealing with the effect of the sibling system on later relationships. Yet Minuchin's family system theory [28] relates to the effect of the sibling system on the marital system and the extended family [29]. Similarly, Eckstein [4] compared the sibling relationship in childhood to the marital relationship. A description of the two systems shows that both are characterized by elements that arise in intensive, related relationships between two people such as: closeness and intimacy, role division, clashes and conflicts, coping methods and more. Additionally, both relationships are symmetrical or complimentary and involve a role division and both are intensive; each of the participants receives immediate feedback on the results of their actions.

Despite the similarities above, there are also some major differences between the two relationship systems based on the process of formation of the relationship and the age of the participants:

The marital connection is one taken out of choice and can be undone, in contrast to the sibling connection with is a blood relation (consanguinity).

The marital connection is viewed as an exclusive dyadic relationship while the sibling connection can extend over a number of siblings simultaneously.

The marital connection is mainly heterosexual while the sibling connection has a large variety of dyadic connections, including both dyads of the same and different genders.

The marital connection embraces tasks unique to it such as the beginning of a family, raising children, earning a livelihood and more.

There are some findings in the literature which point to the development of individuation as a critical component affecting psychological and social functioning, in the context of interactions with the peer group and with the spouse [30, 31]. A number of studies $[32,33]$ claim that although the development of individuation is dependent on many variables, the sibling system is an especially influential one.

Consistent findings in Toman's research $[34,35]$ point to more intimate relationships among siblings when the age difference between the sibs is less than six years. Thus there is greater potential for spouses who experienced this kind of sibling relationship in their youth to develop close, intimate relationships with their partner in adulthood--as well as the conflicts and tensions that are also typical of sibling relationships characterized by this range.

In summary: the literature review demonstrates that there are, indeed, studies dealing with the effect of the sibling system both on molding the personality of the adult [29], and on the parent-child relationship [36-38]. However, few studies have examined the connection between the structure of the sibling system and the individual's present intimate relationship i.e. the couple system. There are studies in the domain of 
the family that show how the developing parent-child relationship is transferred by children to later significant adult relationships, such as the couple relationship or to their own children $[29,31]$. Thus we can hypothesize a possible influence of the sibling system on the couple system.

\section{RESEARCH HYPOTHESES}

Based on the literary review, this study examines the connection between the birth order, traits and emotions within the sibling system, vis-à-vis the couple system--a sphere that has not been researched in depth until now. Therefore the present article contends that there is a connection between the traits, emotions and roles of an individual in the sibling system (in accordance with his/her birth order), and his/her traits, emotions and roles in the later couple system. Research's hypotheses are as follows:

H1. There will be a correlation between traits that characterize first-born, middle and youngest children in the sibling system and traits that characterize them in the couple system.

H2. There will be a correlation between emotions that characterize first-born, middle and youngest children in the sibling system and their emotions as they are expressed in the couple system.

H3. Birth order in the family-of-origin will be related to conceptions of the division of roles in the couple system.

\section{METHOD}

\section{Subjects}

The study includes 69 individual participants aged 20-50, of which 41 were women (59\%) and 28 men (41\% of sample). All participants are spouses in couple relationship that extend from one to ten years. 69 subjects $-32 \%$ were 'firstborns' in their origin family; $34 \%$ subjects were 'middle child' and $32 \%$ subjects were 'youngest'. In accordance with research's consideration of the effect of sibling relations, no subjects were single child in their family of origin.

Recruitment of participants and achieving cooperation was done by the snowball method, starting from the researcher's social surrounding. All participants gave their agreement to participate before filling out the questionnaire.

\section{Tools}

A questionnaire was developed for the purpose of the present study, containing the following sections:
Background Variables - including: age, gender, position in the family of origin; economic status in the family of origin; number of siblings in the family of origin; age difference in the couple system.

Traits and Emotions in the Parental System - Participant's perception regarding traits and emotions in the sibling system was measured. The participants were presented with 16 statements regarding the sibling system, 7 of which depict traits (e.g.: restrained, responsible, rebellious) and 8 depict emotions (e.g.: jealousy, confidence, loneliness). Subjects were asked to rate items in a 5-points Likert scale ranging from 1 ("Definitely agree") to 5 ("Disagree very much"). Cronbach's alpha reliability was .60 for the traits scale and .67 for the emotions scale.

Traits and Emotions in the Couple System - Participant's perception of traits and emotions in the couple system was measured, using the same 16 items as those used in the sibling system scale, with the addition of 2 items regarding need and dependence. Here, subjects were asked to rate items referring to their couple system. Cronbach's alpha reliability coefficient was found to be.52 for traits; and .63 for emotions.

Role Division in the Couple System - This section contains 10 statements regarding the division of roles between spouses. Participant were required to define how the division of roles between themselves and their spouses, was carried out in daily life, rating items on a 5-points Likert scale ranging from 1 ("Definitely agree") to 5 ("Disagree very much"). The scale was constructed according to [39] and adapted to the Israeli reality according to the Ruth Katz questionnaire [40]. Cronbach's alpha reliability coefficient for role division was found to be .71 .

\section{Data Analysis}

In order to test hypotheses $1 \& 2$, pearson correlations were measured between traits and emotions in the sibling system and in the couple system, for first-borns, middle and youngest children..

In order to test hypothesis 3, a one-way ANOVA was conducted, to measure the effect of birth order (the independent variable) on role division in the couple system (the dependent variable).

\section{FINDINGS}

Means and Standard Variations for research variables traits and emotions in the sibling system, in the couple system and perception of role division - for different birth order subjects are presented in Table $\mathbf{1}$ below:

Table 1. Mean and Std. of Research Variables - for Firstborns, Middle Child and Youngest Subjects

\begin{tabular}{|c|c|c|c|c|c|c|c|c|c|c|}
\hline \multirow{2}{*}{ Variable / Position in Origin Family } & \multicolumn{2}{|c|}{$\begin{array}{c}\text { Traits in Sibling } \\
\text { System }\end{array}$} & \multicolumn{2}{|c|}{$\begin{array}{l}\text { Emotions in Sib- } \\
\text { ling System }\end{array}$} & \multicolumn{2}{|c|}{$\begin{array}{c}\text { Traits in } \\
\text { Couple System }\end{array}$} & \multicolumn{2}{|c|}{$\begin{array}{c}\text { Emotions in Cou- } \\
\text { ple System }\end{array}$} & \multicolumn{2}{|c|}{ Role Divisior } \\
\hline & $\mathbf{M}$ & Std & $\mathbf{M}$ & Std & $\mathbf{M}$ & Std & M & Std & $\mathbf{M}$ & Std \\
\hline Firstborns $\left(\mathrm{n}=\_24 \_\right)$ & 2.8 & 0.3 & 3.6 & 0.7 & 3.2 & 1.0 & 3.3 & 0.6 & 3.5 & 0.6 \\
\hline Middle child $\left(\mathrm{n}=\_20 \_\right)$ & 2.7 & 0.4 & 2.9 & 0.3 & 3.3 & 0.6 & 3.4 & 0.5 & 2.7 & 0.4 \\
\hline Youngest $\left(\mathrm{n}=25 \_\right)$ & 2.7 & 0.4 & 3.0 & 1.0 & 2.8 & 0.8 & 3.1 & 0.7 & 2.9 & 0.3 \\
\hline
\end{tabular}




\section{H1: Traits in Sibling and Couple Systems}

Hypothesis 1 claims to a correlation between traits of first-borns, middle and youngest children in the sibling system and their traits as they are expressed in the couple system. Table 2 presents Pearson's correlations between the research variables. According to Table 2, significant correlation were found between traits in the sibling system and traits in the couple system, for first-borns $(\mathrm{r}=.641 \mathrm{p}<.01)$ and for middle children $(\mathrm{r}=.58 \mathrm{p}<.01)$. However, no such significance was found for youngest children $(\mathrm{r}=.294$, $\mathrm{p}>$.173.).

Therefore, transfer of the same traits from the family of origin to the couple relationship, was only found among first- and middle-born children.

\section{H2: Emotions in Sibling and Couple Systems}

Hypothesis 2 states that there is a correlation between the emotional atmosphere that characterizes first-born, middle and youngest children in the sibling system and their respective emotional atmosphere in the couple system. As shown in Table 2 above, there was found a significant correlation for all three groups $(\mathrm{r}=.516 . \mathrm{p}<.05$ for first-borns; $\mathrm{r}=.463$, $\mathrm{p}<0.05$ for middle children; and $\mathrm{r} .=.644, \mathrm{p}<0.01$ for youngest children).

In other words: the more positive the emotional atmosphere in the sibling system, the more likely it was to be replicated to the couple system.

\section{H3: Birth Order and the Division of Roles in the Couple System}

Hypothesis 3 states that there is a relation between the roles that characterizes first-born, middle and youngest children in the sibling system and the later division of roles in their couple system. A one-way ANOVA was conducted to test this hypothesis.
The results did not show any significant variances of the variable role division between first-born, middle and youngest children $\left(\mathrm{F}_{(2,67)}=0.344\right.$, n.s. $)$.

In other words: no relation was found between birth order in the family-of-origin and role division in the future couple system.

\section{DISCUSSION}

It is important to note that the study was conducted in a Western society, not a traditional one.

This study demonstrates a correlation between the emotional atmosphere in the sibling system as experienced by the child in all birth orders, and the emotional atmosphere in the couple system. The following emotions were tested: envy, inferiority, anger, self confidence, loneliness, serenity and frustration.

One explanation for this phenomenon relates to the emotional heritage acquired by the individual in the sibling system. Emotional heritage is of great consequence when compared to other traits that one can adopt throughout life, since the individual's emotional atmosphere is formed in early childhood, thus is deeply rooted in his or her personality. In accordance with this study's findings in the emotional realm, we see that the emotional world of the sibling system is transferred into the couple system, over and above birth order. A positive emotional atmosphere in a family tends to predict a similar atmosphere in the couple system. We can assume that spousal members bring with them the emotional atmosphere they experienced in their families of origin and assimilate it into their own couple systems. These findings corroborate the findings of previous studies such as Toman's $[34,35]$ demonstrate consistent patterns of the transfer of more intimate relationships among siblings to their relationships with their spouses.

In addition, Lawson and Brossart's study in the field of the family [41] demonstrates that relations developed by

Table 2. Pearson's Correlations Between Traits and Emotions in Sibling and Couple System for First-Born, Middle and Youngest Children

\begin{tabular}{|c|c|c|c|c|c|c|c|c|c|c|c|c|c|c|}
\hline & & & \multicolumn{4}{|c|}{ First Born } & \multicolumn{4}{|c|}{ Middle Children } & \multicolumn{4}{|c|}{ Youngest Children } \\
\hline & & & 1 & 2 & 3 & 4 & 5 & 6 & 7 & 8 & 9 & 10 & 11 & 12 \\
\hline \multirow{4}{*}{$\begin{array}{l}\text { First } \\
\text { Borns } \\
(n=22)\end{array}$} & 1 & Tr. sib. & - & & & & & & & & & & & \\
\hline & 2 & Tr. Co. & .641 & - & & & & & & & & & & \\
\hline & 3 & Em. sib. & & & - & & & & & & & & & \\
\hline & 4 & Em. co. & & & .516 & - & & & & & & & & \\
\hline \multirow{4}{*}{$\begin{array}{c}\text { Middle } \\
\text { Children } \\
(\mathrm{n}=\mathbf{2 4})\end{array}$} & 5 & Tr. sib. & & & & & - & & & & & & & \\
\hline & 6 & Tr. Co. & & & & & .58 & - & & & & & & \\
\hline & 7 & Em. sib. & & & & & & & - & & & & & \\
\hline & 8 & Em. co. & & & & & & & .463 & - & & & & \\
\hline \multirow{4}{*}{$\begin{array}{c}\text { Youngest } \\
\text { Children } \\
(n=23)\end{array}$} & 9 & Tr. sib. & & & & & & & & & - & & & \\
\hline & 10 & Tr. Co. & & & & & & & & & .294 & - & & \\
\hline & 11 & Em. sib. & & & & & & & & & & & - & \\
\hline & 12 & Em. co. & & & & & & & & & & & .644 & - \\
\hline
\end{tabular}

* Tr. sib - Traits in the sibling system; Tr. co - traits in the couple system; Em. sib - emotions in the sibling system; Em. co - emotions in the couple system. 
individuals with their parents in childhood are also transferred to other significant relationships such as their relationships with their spouses. This study's findings are also compatible with the family system theory of Minuchin [28] which relates to the influence of the sibling system on the marital system and the extended family.

This study demonstrates a correlation between traits as expressed in the sibling and couple systems among first- and middle-born children. No such correlation was found among youngest siblings. The traits that were tested are: responsibility, peace making, rebelliousness, loyalty, being restrained, pride.

An earlier finding of this study discovered the transfer of the emotional atmosphere from the sibling system to the couple system. In addition, Forer [17] found that the youngest child tends to be the most empathetic; we can hypothesize that this trait is also expressed in the couple relationship of the youngest. Empathy is a term that describes the ability to accurately understand the point of view of the 'other.' It is based on the basic human semblance between two human beings, a similarity allowing one to approach the emotional and cognitive world of the other and understand what transpires in the other's soul, by being empathetic, showing the other that he or she is being heard and understood. In order to be empathetic, a person must be able to set aside his own worldview and personal and theoretical assumptions, to gently uncover the individualistic assumptions and experiences of the 'other' [42]. Thus we can theorize that the youngest's expression of empathy towards his or her spouse may be a willingness to relinquish some of the traits he or she developed within the family of origin, in order to accommodate him or herself to the dominant traits of the spouse.

Another explanation for the lack of correlation of the youngest siblings may be rooted in the methodology of the study. Adler's theory [11] describes the youngest's dominant traits as follows: great ambition, being pampered, and independence. These traits are not included in the traits that are tested in the study's questionnaire. Thus we theorize that if they would appear in the questionnaire, perhaps we would find that the youngest child from the sibling system does transmit these traits to his/her couple system.

In contrast to the study hypothesis, the study did not find differences between the birth-order variable and the division of roles within the family. In our opinion the reason that the variable birth order was not significantly connected to role division in the couplehood, is because the division between male-female participants in the study was not equal: there were 41 women and only $28 \mathrm{men}$. It is also possible that not enough crystal-clear 'male roles' were included in the study's questionnaire. And although the gender variable was included in the definition of functions, the study sample is not large enough to determine how this variable influences the results. Another explanation for the refutation of the hypothesis may be the blurring of roles or functions in the modern family. According to Rabin [43], spousal roles in modern society are shared equally so that there are no outright "male" or "female" roles in most modern families.

\section{STUDY LIMITATIONS}

This study examined the connection between the sibling system, in accordance with the birth order, and the couple system. The study hypothesis was that there is a correlation between one's traits, emotions, and roles in a sibling system (according to birth order) and his/her traits, emotions, and roles in the couple relationship. The study results do not find an effect of birth order on transferring the emotional atmosphere of the family of origin (because the emotional atmosphere was transferred among siblings of all birth orders-firstborn, middle and youngest children). In addition, no influence was found of birth order on a couple's role division. It is possible that these results were affected by some study limitations, mentioned hereinafter:

\section{Size of Population Sample}

Sample size (69 participants) may not be broad enough to yield any kind of distribution or variance among siblings according to their birth order in the family of origin. In addition, the proportion of women to men in the study was asymmetrical---about $60 \%$ women versus only $40 \%$ men.

\section{Sampling Method}

The snowball method was used to recruit the study population. This method does not necessarily yield a representative sample of the population and does not allow control over characterization of the study population.

\section{Measures}

It is worth mentioning that the reports of subjects regarding their sibling system were made at a many years distance, and we can not rule out that some of the observed correlations were due to common method variance and some degree of reporter bias. A much stronger case would include data from siblings. Additionally, an analysis of certain traits and their adaptation with certain birth order positions was not done here.

\section{Mediating Variables}

In this study, two possible mediating variables were not measured, neither discussed. These are: parental practices in the family of origin, and personality traits. As was pointed out by an extensive body of literature [2,36], parent's relationship with their children and within themselves are one of the most decisive factors determining the emotional atmosphere in which an individual child, as well as the sibling system, grows and develops. Further empirical attention should be given to the study of sibling system's' effect, above and beyond the variance in marital relationship explained by parents and the parental system.

Additionally, this study's data do not enable us to rule out the influence of personality. Traits like neuroticism, for example, were found to be related to marital satisfaction [44]; therefore, any variance observed in traits and emotions in the couple system, might be explained by means of subjects' personality index. In the future, an exploration of siblings' traits and emotions effect on traits and emotions in couplehood should include the measurement and neutralization of certain personality traits.

\section{Recommendations for Future Research}

Future research can be based on findings of this study which proves a correlation between the emotional atmosphere in the sibling system to the emotional atmosphere in the couple system. In other words: the emotional atmosphere 
absorbed by the individual in the family of origin, accompanies him or her to the couple relationship as well.

Suggested future study hypothesis: To conduct a longitudinal study that will examine whether long-term psychological therapy can improve the emotional atmosphere that the individual assimilated in his/her family of origin, and then transferred to the couple relationship. The study should track those couples who seek therapy to create some kind of change in the family dynamics, and then keep tabs on the family after they end therapy. The study would check whether the spouses were able to change the negative emotional atmosphere in the couple system, which they were used to in the family of origin.

We suggest to examine couples who are married more than ten years, since young marrieds have a tendency to view their spouses, as well as their entire couple system, in a more positive light.

This study shows that youngest siblings (as opposed to firstborn and middle children) do not transfer the characteristics they adopted in the sibling system, to their adult couple system. Therefore we suggest to investigate couple relationships among youngest siblings to examine why they do not transfer these traits. Perhaps this finding is connected to Forer's claim (1976), that youngest siblings develop greater abilities of empathy.

And additional study in this domain can focus on traditional societies characterized by large families (with numerous children). We theorize that siblings in these kinds of families will take upon themselves parental roles. In such a population, we theorize that children will preserve roles and transfer them from their family of origin to the couple system in a far more pronounced, statistically significant manner--in comparison to the present study population.

Dreikurs' book (2000) contains an attached questionnaire that examines the family system and early childhood memories and probes the lifestyle of the patient/client with an emphasis on sibling relationships and birth order. If there will be another study on this subject, we recommend making use of this valuable questionnaire which could contribute much information and confer greater reliability to the study's findings.

\section{THERAPY PRACTICES}

\section{Couple Therapy}

Pre-marital counseling, based on therapeutic techniques that examine the couple's perception of the couple system in their family of origin, will help to transfer positive elements to their future couple system and make the couple aware of patterns that could be stumbling-blocks in their marriage. This proposal leans on the view that awareness is the first step in creating successful, fulfilling couple intimacy.

In treating married partners, the couple therapist should encourage the spousal members to talk about their childhood memories and the family system in their family of origin, while emphasizing their emotions in the past and present and the similarities / differences in the emotional atmosphere of the two systems (the sibling system and the couple system). In this way, the subject can be brought to their awareness so as to work together on a recommended, feasible process of change.

\section{Family Therapy}

We encourage comprehensive therapy in the family system out of the belief that when there is a problem, it has great influence on all the family members as individuals and on the entire family as a system. In order to create change, the therapist must identify problematics in the family atmosphere and encourage communication and openness to change among all the family members. The therapist must counsel, direct, encourage, mediate and guide. We believe that this kind of change will contribute to the feelings and experiences of all the members of a family and, of course, will have great effect on the future spousal relationships.

\section{Group Therapy}

In line with the findings of our study and based on the therapeutic doctrine of Alfred Adler (1870-1937), we view the family of origin as the behind-the-scenes force in forming the child's emotions, traits and roles. Parents can encourage either success or failure in their children, by their encouragement or reproof. Parents determine the family atmosphere and mold the patterns of interpersonal relationships within the family. They also represent the prototype of male-female roles, thus contributing to the future couple systems of their children. Thus we recommend organizing parent's groups with the purposes of providing counseling, guidance and encouraging awareness. Emotions such as frustration, negativity/opposition and rejection will disappear when parents learn to understand their children better and find appropriate methods for treating problems. The group could also include siblings who assume parental roles (in accordance with their ages and maturity levels).

\section{REFERENCES}

[1] Hammond SW. Blueprints from the past: character work perspective on siblings and personality formation. In: Kahn MD, Lewis KG, Eds. Sibling in therapy: Life span and clinical issues, W.W.Norton \& Company, New York 1988.

[2] Amato PR, DeBoer DD. The transmission of marital instability across generations: relationship skills or commitment to marriage? J Marriage Fam 2001; 63: 1038-51

[3] Cohen M. Intellectual achievements of siblings in late childhood, the connection to birth order, normal birth, range between births, and sex [Hebrew]. Unpublished doctoral dissertation, Hebrew University, Jerusalem, Israel 1982.

[4] Eckstein Y. Sibling relationship as prototype for close relationships: comparison of sibling relationships in childhood to marital relationships [Hebrew]. Unpublished master's thesis, Haifa University, Haifa, Israel 1997.

[5] Bank S, Kahn MD. The sibling bond. Basic Books, New York 1997.

[6] Bozard JHS, Boll ES. The large family system. Philadelphia: University of Pennsylvnaia Press 1956.

[7] Minuchin S. Families and family therapy. Cambridge, Mass., Harvard University Press 1974.

[8] Adler A. You and your life [Ata ve'chayecha, Hebrew translation], Tel Aviv: Alfred Adler Institute 1984; 103-11.

[9] Ziv A. Psychology--Science of understanding man. Tel Aviv: Am Oved 1995.

[10] Mahler V. Psychology--Volume B. Tel Aviv: Am Oved, Culture and Education 1979; 247-78.

[11] Adler A. The practice and the theory of individual psychology. Paterson, NJ: Littlefield Adams 1959.

[12] Daniel J, Ziegler, Larry AH. Personality theories: basic assumptions, research and applications. McGraw-Hill, New York 1992; pp. 150-3. 
[13] Fishler R. Birth order and gaps/imparities in the mother-child view of the relations between them [Hebrew]. Unpublished master's thesis, Bar Ilan University, Ramat Gan, Israel 1982.

[14] Zagonc RB, Markus GB Birth order and intellectual development. Psychol Rev 1975; 82: 74-88.

[15] Belmont L. Birth order, intellectual competence, and psychiatric status. J Indiv Psychol 1974; 33: 97-104.

[16] Breland HM. Birth order family configuration and verbal achievement. Child Dev 1974; 45(4): 1011-9.

[17] Forer LK. The birth order factor. David McKay Company, Inc: New York 1976.

[18] Aspanyoli-Hazan H. The connection between the variables: family size, birth order and the parental approach as perceived by the child, vis-à-vis the intellectual level of the child [Hebrew]. Unpublished doctoral dissertation, Bar Ilan University, Ramat Gan, Israel 1989.

[19] Ganor A. Self-development in early childhood: the effect of emotional availibility in the dyad, gender and birth order on selfidentification in the mirror [Hebrew]. Unpublished master's thesis, Haifa University, Haifa, Israel 1999.

[20] Dunn J. Sister and brothers. Dunn Judy, USA 1985.

[21] Hjelle LA, Ziegler DJ. Personality Theories: Basic Assumptions, Research and Application $4^{\text {th }}$ ed. McGraw-Hill: New York, NY 1992; pp. 154-60.

[22] Brody,G. Sibling relationship quality: its causes and consequences. Annu Rev Psychol 1998; 49: 1-24.

[23] Buhrmester D. The developmental courses of sibling and peer relationships. Basic Books, New York 1992.

[24] Newman J. Effects of family size and sibling spacing on sibling relationship. In: Child care health and development 2006; 122: pp. 285-305.

[25] Bowlby J. Attachment and loss. Basic Books, New York 1982; vol. 1.

[26] Teti DN, Abbard KE. Security of attachment and infant siblings relationships: a laboratory study. Child Dev 1989; 60: 1519-28.

[27] Bandura A. Social foundation of thought and action: a social cognitive theory. Englewood Cliffs, NJ: Prentice-Hall 1986.
[28] Minuchin P. Relationship within the family: a systems perspective on development. In: Hinde RA, Stevenson-Hinde J, Eds. Relationships within families: mutual influences. Oxford, England: Clarendon press 1988; pp. 7-26.

[29] Lawson DM, Brossart DF. The association between current intergenerational family relationships and sibling structure. J Couns Dev 2004; 82 (4): 472-82.

[30] Bray JH, Hervey DM. Intimacy and individuation in young adults: Development of the young adult version of the personal authority in the family system questionnaire. J Fam Psychol 1991; 6: 152-63.

[31] Williamson DS. The intimacy paradox: personal authority in the family system. New York: Guilford 1991.

[32] Byrd B, DeRosa A, Craig SS. Adult who is an only child: Achieving separation or individuation. Psychol Rep 1993; 73: 171-7.

[33] Sputa CL, Paulson SE. Birth order and family size: inferences on adolescents' achievement and related parenting behaviors. Psychol Rep 1995; 76: 43-51

[34] Toman W. Family therapy and sibling position. Northvale, NJ: Aronson 1988

[35] Toman W. Family constellation. New York: Springer 1993

[36] Lye DN. Adult child-parent relationships. Annu Rev Sociol 1996; 22: 79-102.

[37] Spitze G, Logan J. Sibling structure and intergenerational relations. J Marriage Fam 1991; 53: 871-84.

[38] Powell B, Steelman LC. Beyond sibship size: sibling density, sex composition, and educational outcomes. Soc Forces 2000; 69: 181206.

[39] Blood \& Wolf. Husbands and wives: the dynamic of marital living. New York: Free Press 1960

[40] Lawson DM, Brossart DF. Intergenerational transmission: individuation and intimacy across three generations. Fam Process 2001; 40: 429-42.

[41] Rosenheim A. Man meets himself. Jerusalem: Shocken press 1990.

[42] Rabin K. Equal partners--good friends. Empowerment of couples through therapy. Tel Aviv University: Ramot 1998.

[43] Kamey BR, Bradbury TN. Neuroticism, marital interaction, and the trajectory of marital satisfaction. J Pers Soc Psychol 1997; 72: $1075-92$

(C) Hadas Doron; Licensee Bentham Open.

This is an open access article licensed under the terms of the Creative Commons Attribution Non-Commercial License (http://creativecommons.org/licenses/by$\mathrm{nc} / 3.0 /$ ) which permits unrestricted, non-commercial use, distribution and reproduction in any medium, provided the work is properly cited. 